\title{
Review
}

\section{Present status of freshwater aquaculture in India - A review}

\author{
P. JAYASANKAR \\ ICAR-Central Marine Fisheries Research Institute, Kochi - 682 018, Kerala, India \\ e-mail:pjayasankar@yahoo.com,p.jayasankar@icar.gov.in
}

\begin{abstract}
Aquaculture is a rapidly growing fisheries sector in India with an annual growth rate of over 7\%. Freshwater aquaculture contributes over $95 \%$ of the total annual aquaculture production of 5.77 million $t$. Technologies of induced carp breeding and polyculture of the three Indian major carps (Catla catla, Labeo rohita and Cirrhinus mrigala) as well as 'composite carp culture' with the addition of three exotic carps (Hypophthalmichthys molitrix, Ctenopharyngodon idella and Cyprinus carpio) in ponds and tanks brought about perceptible upward shift in freshwater aquaculture production. Of late, the sector has been witnessing diversification with the inclusion of medium and minor carps, catfishes and murrels. Andhra Pradesh and West Bengal are the top producers of freshwater fish through aquaculture. System diversification has resulted in optimum productivity of 3-6 tha $\mathrm{yr}^{-1}$. Public and private carp hatcheries produce around 40 billion fry. Fish requirement by 2020 is expected to touch 15 million $\mathrm{t}$, of which around 9 million $\mathrm{t}$ would need to come from freshwater aquaculture. Input-related, social and environmental constraints of aquaculture in India need to be tackled through horizontal and vertical expansion, technology as well as climate change mitigation and adaptation, for sustainable development.
\end{abstract}

Keywords: Blue revolution, Constraints, Diversified species, Freshwater aquaculture, Sustainable development, Technology

\section{Introduction}

At the World Food Summit organised by the Food and Agriculture Organisation (FAO) in Rome in 1996, the participating countries committed to reduce the number of malnourished people in the world by half by the year 2015 (Haylor, 2004). It is a well-known fact that fish is rich in protein and essential amino acids. It is also a good source of calcium, vitamin $A$ and $\mathrm{B}_{12}$ and omega-3 fatty acids. People irrespective of age who do not get sufficient nutrients from cereal-based diets, would be benefited from the inclusion of fish in the diet. Aquaculture not only supplies dietary essentials for human consumption, but provides excellent opportunities for employment and income generation, especially in the more economically backward rural areas. Sixty million people are directly engaged, part time or full time, in primary production of fish, either by fishing or in aquaculture, supporting the livelihoods of $10-12 \%$ of world population (FAO, 2016). Aquaculture currently accounts for over $50 \%$ of the global food fish consumption (Subasinghe et al., 2009).

Globally India stands second in culture fisheries production. China, with world's one fifth of population produces one-third of total fish harvested and two thirds of fish cultivated (FAO, 2016). While in India, the culture system is based on 3-6 species combination, Chinese have 10 or more species in a single pond thus maximising productivity. Indian aquaculture has demonstrated a six and half fold growth over the last two decades, with freshwater aquaculture contributing over $95 \%$ of the total aquaculture production. India is bestowed with 3.15 million ha of reservoirs, 2.36 million ha of ponds and tanks as well as 0.19 million ha of rivers and canals. Freshwater aquaculture with a share of $34 \%$ in inland fisheries in mid $1980 \mathrm{~s}$ has increased to about $80 \%$ in recent years (DADF, 2017). The technologies of induced carp breeding and polyculture in static ponds and tanks have brought about remarkable upward trend in aquaculture productivity and turned the sector into a fast growing industry. The research and development programs of the Indian Council of Agricultural Research (ICAR), as well as the development support provided by the India Government through a network of Fish Farmers' Development Agencies (FFDA) have been the principal vehicles for this development. Additional support has been provided by several other organisations, state departments and financial institutions. So far, about 0.65 million ha of water area has been brought under fish farming covering 1.1 million beneficiaries. Currently the average annual yield is around $3 \mathrm{tha}^{-1}$. At the same time, training has been imparted to about 0.8 million fishers (DADF, 2017).

Despite the importance of freshwater aquaculture in Indian food sector, no extensive reviews have been made on the sector. However, preliminary review on recent advances in freshwater aquaculture (Jayasankar, 2014), documentation on freshwater aquaculture technologies for bringing about blue revolution (Jayasankar, 2017), 
promotion of PPPs (Public Private Partnerships) for technology adoption (Jayasankar and Barik, 2015) and vertical expansion strategy for increasing aquaculture production (Jayasankar and Das, 2015) are available. The present paper forms a comprehensive attempt to review the current status of freshwater aquaculture in India.

\section{Data source}

The statistical information on aquaculture production in India in global context was sourced from FAO (2016) while state-wise resource and production information within the country was obtained from Department of Animal Husbandry Dairying and Fisheries (DADF, 2017).

\section{Freshwater aquaculture production in the global context}

Global fish production stands at 167 million t, of which $44 \%$ (73.8 million $t)$ is contributed by the aquaculture sector (FAO, 2016). Global capture fishery is presently at crossroads with over $70 \%$ of the resources exploited and therefore aquaculture is the only option to fill up the gap of much of the future demand for fish. Aquaculture is the fastest growing animal food-producing sector, growing at a rate more than $7 \%$ annually. Many studies have pointed towards a positive scenario for the role of aquaculture in providing the much-needed animal protein to the world population (Tidwell and Allan, 2001; Sugiyama et al., 2004). Importance of freshwater aquaculture in the global aquaculture production is evident as it accounted for $63.8 \%$ of global total of $47,102,391 \mathrm{t}$ (FAO, 2016).

\section{Freshwater aquaculture production trends in India}

Aquaculture production in India has been increasing steadily over the years and during 2015-16 the figure was

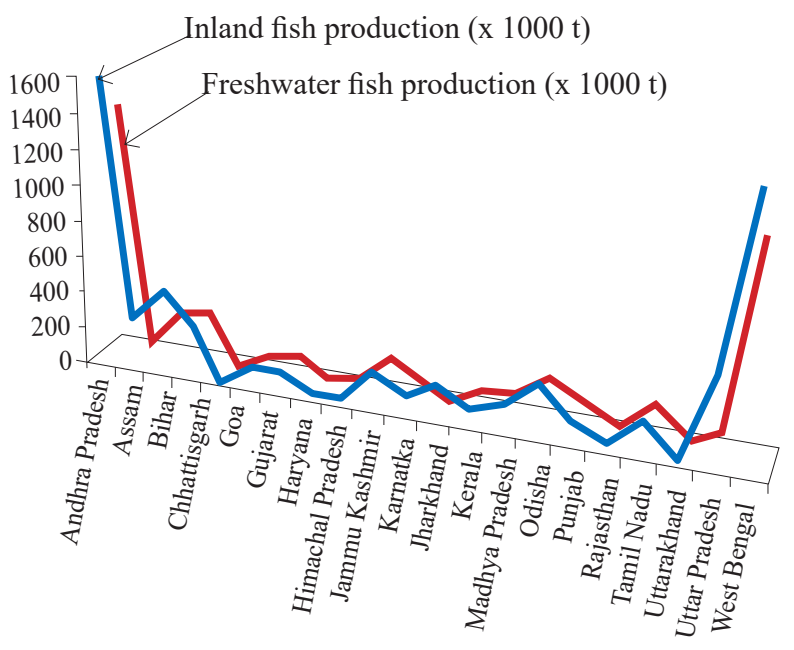

Fig. 1. State-wise inland and freshwater fish production in India about 5.77 million $t$ (Fig. 1). Bulk of the carp production in the country is contributed by the three Indian major carps (IMCs), namely catla (Catla catla), rohu (Labeo rohita) and mrigal (Cirrhinus mrigala). Exotic species, namely silver carp (Hypophthalmichthys molitrix), grass carp (Ctenopharyngodon idella) and common carp (Cyprinus carpio) form the second important group. National freshwater fish productivity has registered marked rise from $0.6 \mathrm{t} \mathrm{ha}^{-1} \mathrm{yr}^{-1}$ (1974) to $3 \mathrm{t} \mathrm{ha}^{-1} \mathrm{yr}^{-1}$ at present. Many farmers have demonstrated productivity levels as high as 8-12 $\mathrm{t} \mathrm{ha}^{-1} \mathrm{yr}^{-1}$ (Jayasankar, 2014). Further, freshwater aquaculture production has begun to diversify, incorporating medium and minor carps, catfishes and murrels. The only species from the freshwater sector that goes to the export market has been the giant freshwater prawn (Macrobrachium rosenbergii), while carps and other finfishes are grown for the domestic market. Recently, production of $M$. rosenbergii has plummeted, while that of white legged shrimp Penaeus vannamei enhanced considerably.

With a national per capita consumption of $11 \mathrm{~kg}$, fish is recognised as one of the chief components in the domestic food security in India (Jayasankar and Barik, 2015). Freshwater aquaculture is a homestead activity in several parts of the country. Besides contributing to the nutritional security, it also helps in bringing additional income to the poor rural households. Aquaculture brings about socio-economic development in terms of income and employment through the use of unutilised and underutilised resources in many parts of the country.

Polyculture with low to moderate inputs, particularly organic fertilisers and feed is practiced in village water bodies (VWBs). Entrepreneurial acumen supported by innovative management brought about change in the multi-use and multi-ownership of VWBs across India. This notwithstanding, perceptible shift in fisheries intensity is being felt in certain states in the country. Poaching, shortage of water and finance are the major problems faced by fish farmers. Sustainable growth of aquaculture in VWB is entailed to meet the rising demand for fish.

Formulation and implementation of policies on resource utilisation and leasing are state subjects. They are done with a good intention of uplifting the poor and strengthening co-operative system of local communities. FFDA programme of the central government supported initially with World Bank aid did most of the initial funding for initiating aquaculture in inland water bodies. Technical, financial and extension support is provided to fish farmers for taking up culture-based fishery in village ponds and tanks (Katiha et al., 2005). 


\section{Major players in freshwater aquaculture in India}

Andhra Pradesh, West Bengal, Bihar and Chhattisgarh are among the top producers of freshwater fish through aquaculture. Andhra Pradesh producing around 15 lakh t of fish of which $92 \%$ is supplied to other states and West Bengal with a current production of around 13 lakh $t$ of fish and still sourcing fish mainly from Andhra Pradesh are the two top producers of freshwater fish in the country (Jayasankar, 2014). Bihar, Chhattisgarh, Assam and Jharkhand are also enhancing their stakes in freshwater aquaculture production. Bihar and Chhattisgarh together produce around 3 lakh t; while the former state has negligible dependence on fish from other states with about 20\% marketed to outside states; the latter gets about 25\% from Andhra Pradesh for internal market. Assam produces around 2 lakh t, though still sources around 30\% of their fish requirement from other states considering high domestic demand. Jharkhand produces about 1 lakh $\mathrm{t}$ freshwater fish, but still procures $20 \%$ of its need for internal market from outside states. Jharkhand is all poised to boost its freshwater fish production significantly through cage culture of pangas in reservoirs (Jayasankar, 2014).

\section{Inland fish farming and associated considerations}

\section{Aquaculture resources}

India is blessed with rich natural sources for enhancing freshwater aquaculture production: 2.42 million ha of ponds and tanks; 1.07 million ha of beels, jheels and derelict waters; 0.12 million km of canals; 3.15 million ha of reservoirs and 0.72 million ha of upland lakes. Only around $35 \%$ of ponds and tanks are being used currently for aquaculture. Small and marginal farmers, especially in eastern India have ponds of less than 1 ha and are typically homestead ones. State-owned or communitymanaged ponds are generally leased out for periods of 3-5 years (Katiha et al., 2005). Fig. 2 depicts state-wise production figures of various species in India.

Carps

Site-specific input availability and monitory capacity of farmer to invest, influences the type of culture systems adopted in various regions. In extensive aquaculture system, inputs are limited but for the seed stocked. It harnesses natural productivity. On the other hand in semi-intensive system, fertilisation and feeding 'are adopted to enhance productivity. Information is available on composite carp culture; sewage-fed fish culture; weed-based carp polyculture; biogas slurry-fed fish culture; integrated fish farming with poultry, pigs, ducks and horticulture, as well as pen culture (Sinha et al., 1973; CIFA, 2004; ICAR, 2005). The optimum achievable

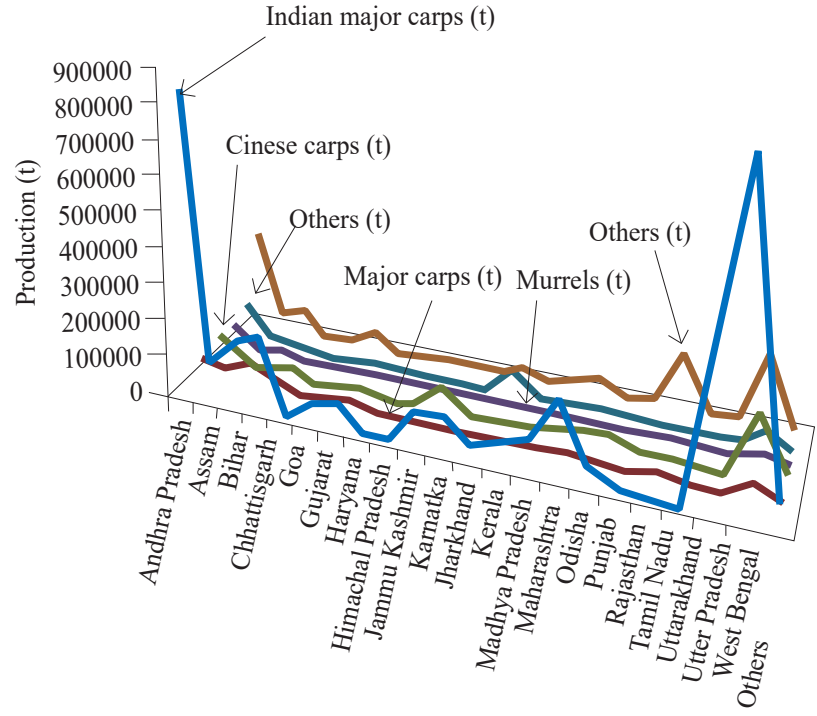

Fig. 2. State-wise production figures of major fish species from freshwater aquaculture in India

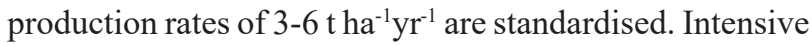
culture systems like cage culture and running-water fish culture have given productions of $10-15$ and $20-50 \mathrm{~kg}$ $\mathrm{m}^{-2} \mathrm{yr}^{-1}$ respectively (Tripathi et al., 2000; Katiha et al., 2005).

Carp culture is practiced as polyculture of the three IMCs (catla, rohu and mrigal) as well as composite carp culture of the three IMCs with the three exotic carps (silver carp, grass carp and common carp). Standard practices in carp culture include: (i) Stocking at combined densities of 4,000-10,000 fingerlings ha $\mathrm{h}^{-1}$; (ii) Pond fertilisation with organic manures from cattle or poultry as well as inorganic fertilisers like urea and single super phosphate and (iii) Supplementary feeding using a mixture of rice bran/wheat bran and groundnut/mustard oilcake in equal ratio. The three IMCs, namely catla (C. catla), rohu (L. rohita) and mrigal (C. mrigala) contribute the bulk of production to the extent of 70 to $75 \%$ of the total freshwater fish production, followed by exotic carps comprising silver carp, grass carp and common carp forming the second important group contributing to the balance 25 to $30 \%$ (FAO, 2017).

Despite the fact that the country also possesses several other cultivable medium and minor carp species which show high regional demand, including L. calbasu, L. fimbriatus, L. gonius, L. bata, L. ariza, Puntius sarana, Hypselobarbus pulchellus, H. kolus and Amblypharyngodon mola as well as several others, commercial farming of these species has been almost non-existent or picking-up slowly. These medium sized carps have initial higher growth rate and market 
acceptability at 300-400 $\mathrm{g}$ which makes them ideal species for intercropping in the major carp farming system. These species can be considered as more suitable for the utilisation of seasonal ponds, which have 5-6 months of water retention. Over the years, incorporation levels of the various species of minor carps and barbs in the IMC based grow-out polyculture system have been standardised.

\section{Catfishes}

Pond culture of catfish involves mainly magur (Clarias magur) and singhi (Heteropneustes fossilis) and is practiced in states like Assam, Bihar, West Bengal and Odisha (Thakur and Das, 1986; CIFA, 2004; ICAR, 2005). Though modern farming techniques for these species advocates monoculture at stocking densities of 20,000-50,000 fingerlings $\mathrm{ha}^{-1}$, inadequate availability of juveniles has restricted these as a component in carp polyculture systems. Considering the high market demand for catfish and the availability of a huge potential resource in the form of swamps and derelict waters, commercial farming of these species is being given important attention at present. Magur (Clarias magur) attains a marketable size of 100-120 $\mathrm{g}$ in a period of 7-8 months of culture. Average production of 3-4 $\mathrm{tha}^{-1}$ magur can be achieved in 8 months culture period. Polyculture of non-air breathing catfishes like Pangasius pangasius, Wallago attu, Sperata seenghala, S. aor and Ompok pabda is being attempted in recent years (Kumar, 2016). During 20082010 phenomenal growth was shown in the culture of exotic catfish pangas, Pangasianodon hypophthalmus. In Andhra Pradesh around $10 \%$ of the area in KrishnaGodavari delta has been occupied by this single species. Major sources of seed are from Bangladesh through our porous border and from West Bengal. Many other states including Chhattisgarh, Jharkhand and Bihar have shown enthusiasm to culture of pangas. Production levels of the species ranges from around 15 to $50 \mathrm{t} \mathrm{ha}^{-1}$ $\mathrm{yr}^{-1}$ (Jayasankar and Giri, 2013). Culture of butter catfish O. pabda has been successfully practiced in West Bengal and Tripura. Availability of seed is a huge constraint, followed by high mortality in larval rearing phase, lack of larval and grow-out feed (Chakrabarthi et al., 2009). Aquatic insects and their larvae are the favourite natural feed; supplementary fish meal-based feed needs $30 \%$ protein. For the first time, with the intervention of Regional Research Centre of ICAR-Central Institute of Freshwater Aquaculture (ICAR-CIFA), Kalyani, one of the progressive fish farmers of West Bengal produced more than 1.5 lakhs of $O$. pabda fingerlings on a commercial basis.

\section{Other finfishes}

Climbing perch (Anabas testudineus), murrels (Channa striatus and C. marulius) and tilapia
(Oreochromis mossambicus and O. niloticus) are other important finfishes which have great potential for commercial aquaculture in India (Khan, 1969). A. testudineus has good market demand in states like West Bengal, Tripura, Assam, Manipur, Jharkhand, Bihar, Odisha and Kerala. Climbing perch is a potential species for culture with high economic value and consumer preference. It also has high medicinal and nutritive value. Like pabda, major constraints for culture are nonavailability of seed, high mortality in larval rearing phase as well as lack of larval and grow-out feed (Kumar et al., 2012). Experiments at ICAR-CIFA showed production up to $1.2 \mathrm{t} \mathrm{ha}^{-1} \mathrm{yr}^{-1}$, with fish attaining marketable size of 50-60 g in one year. Murrels fetch a high price in many states like Punjab, Haryana, Madhya Pradesh, Bihar, Uttar Pradesh, Andhra Pradesh, Karnataka, Tamil Nadu and all North-Eastern States. They are highly preferred because of the flavour, meaty flesh and less intramuscular bones (Kumar et al., 2013). The fishe are fed with boiled and minced poultry offal in combination with rice polish at $5 \%$ of body weight initially which is reduced subsequently to $2 \%$ depending upon their growth. ICAR-CIFA has succeeded in standardising seed production of two species of murrels viz., C. striatus and C. maruleus and an average production of $2 \mathrm{t} \mathrm{ha}^{-1} \mathrm{yr}^{-1}$ is achievable.

\section{Freshwater prawn}

Successful breeding and larval rearing of the giant river prawn $M$. rosenbergii and the monsoon river prawn M. malcolmsonii provide scope for the farmers to diversify their culture (CIFA, 2004; ICAR, 2005). M. rosenbergii is the largest and fastest growing species being farmed and possesses considerable demand both in domestic and international markets. $M$. rosenbergii is cultured either alone or in combination with carps. Monoculture of giant river prawn is mostly confined to earthen ponds with moderate stocking densities of 20,000-50,000 ha- . $^{-1}$. Fertilisation and supplementary feeding can result in a moderate yield of $600-1,500 \mathrm{~kg} \mathrm{ha}^{-1}$ in 8 months using single stocking and both single/multiple harvesting. Polyculture of freshwater prawn juveniles at 10,000-15,000 ha-1 alongside carp at 3,000-4,000 ha-1 has also been demonstrated to be economically viable (Tripathi et al., 2000). Since 2006, production $M$. rosenbergii has been declining drastically due to various reasons including the rise of vannamei farming, reduction in productivity as a result of poor quality seed, poor quality broodstock, increased cost of production, increased operational cost and reduced profit margin. In this regard, development of quality broodstock and ensuring availability of better quality seed is of utmost importance. Considering all these, ICAR-CIFA in collaboration with World Fish, Malaysia 
started a genetic improvement program of $M$. rosenbergii through selective breeding in 2007. Selective breeding for growth has yielded $4 \%$ genetic gain per generation and onfarm field testing of $3^{\text {rd }}$ and $4^{\text {th }}$ generations of improved $M$. rosenbergii was conducted at different places in Odisha, Assam, Andhra Pradesh and Tripura (Pillai et al., 2011).

\section{Fish seed production}

Traditionally carp seeds were collected from the natural water bodies when product quality was low and transportation cost from collection grounds to the farm site was high. The collection season has been short and the quantity of the annual collection fluctuated considerably with the variation of environmental conditions. Deterioration of river environments has resulted in quick decline in both quantity and quality of collection.

Revolution of sorts was created by the induced breeding technique (hypophysation) from latter parts of the fifties. Indian scientists have successfully achieved artificial breeding of Asiatic carps (including IMCs and Chinese carps) by applying this technique and it significantly contributed to the methodology of fish seed production under controlled conditions and as per the choice of the farmer. Carp hatcheries in both the public and private sectors have contributed towards the increase in seed production from 6,321 million fry in 1985-1986 to around 40,000 million fry, produced by around 2000 hatcheries (Jayasankar and Das, 2015).

\section{Resource renovation and horizontal expansion}

It is relevant to ponder as to why the potential of 4-5 $\mathrm{t} \mathrm{ha-1} \mathrm{yr}^{-1}$ productivity in ponds is not realised and national average is hovering around $3.0 \mathrm{t} \mathrm{ha}^{1} \mathrm{yr}^{1}$ ? The reasons could be many, such as erratic monsoon resulting in poor rains or flood like situation, both of which are undesirable; improper maintenance of ponds resulting in poor holding capacity and thus poor production. Renovation of such ponds is to be done by desilting. Increased water use efficiency is critical, which is only about $50 \%$ currently. In situ water harvesting, construction of water harvesting structures and inter-basin transfer of water are measures to improve water use efficiency. Water conservation and increased fish production go hand in hand.

Horizontal expansion has become an important option to boost fish production, since out of 2.414 million ha of ponds and tanks, only about $50 \%$ is presently exploited (Jayasankar and Das, 2015). Further, derelict water bodies could be immensely useful and could be an important resource to boost fish production for meeting the future fish demands of the country. Coastal Odisha for instance, is endowed with large areas of unutilised water bodies like derelict canals and drains. Similarly, Brahmaputra basin of Assam has enormous beels lying idle. There are about 1.3 million ha of beels and other derelict water bodies in the country. Bringing these water bodies into the ambit of fisheries will boost fish production tremendously and hence expansion of fisheries in these water bodies is one of the focus areas of the government for increasing fish production (DADF, 2017).

\section{Vertical expansion - species and system diversification}

With a view to increasing productivity, breeding and culture technologies of diversified groups of freshwater species have been standardised, which include IMCs, minor carps, barbs, catfish, pabda, freshwater prawn (genetically improved), climbing perch and murrel. Some of the effective strategies to enhance productivity include intercropping minor carps and barbs in conventional major carp culture, monoculture of catfish and prawns or their polyculture with major carps and mono sex tilapia culture. System diversifications such as: fish seed rearing based on cluster farming; utilisation of shallow/rain fed ponds for producing stunted fingerlings; adoption of multiple stocking and multiple harvesting; implementation of waste water aquaculture system in those places where nutrient-rich wastes such as sewage, brewery waste and dairy wastes are available; adoption of rice-cum-fish culture system; adoption of integrated farming systems especially in homestead ponds and installation of cage/ pen for culture of fish in open water systems, can bring about increased fish production and productivity.

Sewage-fed fish culture and paddy-cum-fish culture are two important culture systems practiced traditionally in some parts of the country. Sewage-fed fish culture in bheries in West Bengal is an age-old practice. About 5,700 ha are currently utilised for fish culture using primarytreated sewage as input and produces over 7,000 $\mathrm{t} \mathrm{yr}^{-1}$, largely consisting of the major and minor carps. Multiple stocking and multiple harvesting are practiced, with harvest weight of fish usually in the range of 300-500 g. Stocking densities of 10,000-20,000 ha-1 are common, though densities as high as $50,000 \mathrm{ha}^{-1}$ have also been reported from many farms (Jayasankar, 2014).

Generally in paddy fields in lowland areas with medium to semi-deep water, rice-cum-fish culture is undertaken. Fairly strong dykes are provided to prevent the escape of cultivated fish during floods. Fish get shelter in trenches and pond refuges in the paddy fields. Though the traditional rice-cum-fish system relies on natural stocking, modern farming techniques involving major and minor carps stocked at densities of 5,000-10,000 haalongside freshwater prawn are also practiced in different 
places. In a well-managed rice-cum-fish farming system, production levels of 3.5 $\mathrm{t}$ of rice and $0.5-1.0 \mathrm{t}$ of fish per ha can be achieved within a year (Jayasankar and Das, 2015).

Cage/pen culture in open waters offers vast potential for inland aquaculture in the country. The production potential from sustainable cage culture for table fish production is about $50 \mathrm{~kg} \mathrm{~m}^{-3}$ with enormous possibility for further expansion and intensification. Reservoirs, which are largely untapped in India, have great potential for development of fisheries. By promoting technologies like cage culture, the productivity of the reservoirs can be enhanced manifold. Due to large initial investment, this technology has so far not been successfully implemented in India (DADF, 2017).

As per an estimate, the total fish seed required for optimal stocking in the existing ponds, new ponds and reservoirs is about 60,000 million fry. As against this, the seed production in 2015-16 was about 40,540 million fry. Thus there is a gap of about 19,460 million fry (DADF, 2017). Setting up of brood banks and hatcheries across the country should be prioritised. Emphasis should be laid on quality seed with improved economic traits. Poor productivity can be linked to poor genetic conditions of broodstock maintained in several hatcheries. Scientific way of broodstock quality improvement includes selective breeding, genome manipulation, marker-assisted selection, transgenesis and genome selection (Sinha and Jayasankar, 2014). Time, cost and pond facilities affect stocking of ponds with fingerlings. One common cause of crop failure can be traced to stocking with fry in growout ponds. Significant enhancement in carp production has been achieved in Andhra Pradesh by stocking with stunted fingerlings (yearlings and "zero point") at the rate of 5000 nos. ha-1 (Jayasankar and Das, 2015).

\section{Feed technology and feed management}

Among the different facets of aquaculture, feed stands out as the most expensive component, costing about $60-70 \%$ of the total expenditure. Small and marginal farmers with traditional mind-set and limited resources have not yet embraced supplemental feeding technique. However, it is a welcome piece of information that in recent times every farmer in West Bengal is adopting supplemental feeding of cultured fish. Conventional feeding results in feed conversion ratio (FCR) as high as 3-5. The scenario becomes even more challenging considering stiff competition for feed concentrate from the poultry and dairy sectors. In Andhra Pradesh, pellet feed with balanced nutrition are given to pangas. Feed cost can be substantially reduced by resorting to farm made feeds made from locally available cheap plant materials. Complete replacement of fish meal is possible for carps, which can further reduce the cost. Establishment of low cost feed mill in regions where freshwater aquaculture is prospering is entailed. Current production-demand ratio of feed concentrate is $44: 143$, indicating deficiency of $69 \%$ (Jayasankar, 2014).

\section{Disease diagnostics, surveillance and management}

Intensification of farming activities always has a "side effect" of disease incidences and outbreak. As yet we have little information on real-time crop loss due to diseases. In one such cases, an estimated loss of ₹29500 $\mathrm{ha}^{-1} \mathrm{yr}^{-1}$ has been reported in argulus-inflicted carp (Sahoo, P. K., per. comm.). ICAR-funded National Surveillance Programme for Aquatic Animal Diseases is a step in right direction, which is expected to identify, document and analyse prevailing and emerging diseases in aquaculture sector. Cutting edge research on immunology, microbiology, molecular biology and nanotechnology needs to be strengthened for addressing the fish health management issues. Quarantine protocols, diagnostics, immunoprophylaxsis, probiotics, bioremediation and chemotherapeutics are available (Jayasankar, 2014).

\section{Technology interventions for aquaculture development}

Technologies on breed improvement, hatchery, seed quality verification, broodstock diet, fish health management, species diversification and post-harvest value addition are available (Jayasankar, 2014; 2017) which can augment freshwater aquaculture development in the country. Improved variety of rohu, "Jayanti" is a step forward to improve farm productivity. After eight generations of selection, $18 \%$ higher growth realisation per generation was achieved. The field testing of "Jayanti" rohu has been carried out in Odisha, West Bengal, Andhra Pradesh, Tamil Nadu and Punjab with encouraging results. In India, 16 states have already received "Jayanti" rohu from the nucleus i.e., ICAR-CIFA, Bhubaneswar, as well as from different multiplier units, earning high acceptance level from the fish farmers and hatchery owners, especially because it has proved to be feed neutral and effective under all culture practices. Impact assessment study further confirmed the superiority of "Jayanti" strain of rohu over the normal rohu (Das Mahapatra et al., 2016).

Another notable achievement is a PCR based identification kit which can identify Labeo rohita (rohu), Catla catla (catla) and their hybrid in the early life stages using a house keeping nuclear gene. This technology would really be of great use for those producers and buyers for screening of quality seeds and moreover it would be a stepping stone for seed certification programmes for both government and private hatcheries. In a survey conducted by the present author and team in West Bengal, Bihar, 
Odisha and Gujarat, it has been found that on an average $22.8 \%$ of the total hatchery produced seeds are hybrids (Mohanty et al., 2016).

\section{Major constraints for development of aquaculture}

Availability of good quality seed, land leasing tenure, social issues like poaching, water availability, feed availability, access to technology at grass root level, climate change and credit facility are the prominent constraints of freshwater aquaculture development in India.

Vignesh et al. (2017) have identified inadequate availability of quality seeds as the top one among 14 constraints affecting freshwater aquaculture in Thanjavur District of Tamil Nadu, others being short supply of water, high cost of supplementary feed, high cost of electricity, non-availability of skilled labour, prevalence of disease outbreak in culture ponds, poaching, high mortality during culture period, low farm gate price, problem of direct selling to buyers, low productivity, poor quality of carp seeds and low net returns. Experience shows that similar constraints exist in other states also, where freshwater aquaculture is practiced.

De Silva and Soto (2009) have commented that climate change will impact on water availability, weather patterns and extreme rain events. The anticipated positive impact of rise in temperature might not always be existent since events like increased eutrophication could negatively impact aquaculture in India. Sustaining partnerships between public funded national agriculture research institutes and the private sector are key drivers of technological progress. Having stated that, lack of access to credit/finance is still a stumbling block for progress in aquaculture sector. Roy (2015) opined that public-private investments in researching and developing genetically improved fish strains have the potential to provide attractive economic returns to the private sector and to meet the public need for improved seed quality.

Some of the important policy elements for managing constraints in freshwater aquaculture include (Salim et al., 2014):

$>$ Policy support to release large tract of unutilised unproductive non-remunerative agricultural lands for the development of aquaculture

$>$ Supply of good quality feeds with low FCR through indigenous feed technology

> Establishment of broodbank and certified hatcheries in order to ensure supply of good quality seed

$>$ Encourage growing diversified indigenous species and using diversified culture systems
$>$ Use modern technology for increasing production and productivity

$>$ Policy support for encouraging credit and insurance agencies in extending adequate lending and insurance coverage to the sector

$>$ Policy directions for GIS-based mapping of land and freshwater resources and establishment of nodal database centres

$>$ Bring in professional management of the sector appointing technical heads in state departments and capacity building of their officers

$>$ Encourage research and development in innovative technology generation using indigenous knowledge according to the needs of the farmers.

\section{Conclusion}

Responsible aquaculture and prevention and management of aquatic diseases, organic farming and induced breeding are some of the other challenges to be addressed in this sector for improving productivity. Achieving growth rate of about $8 \%$ annually on a sustainable basis over a period of five years would be possible only if production is targeted at 15 million $t$ by end of 2019-20 (as against production of 10.79 million $t$ at the end of 2015-16), of which at least 11 million $t$ would need to come from the inland sector and freshwater aquaculture is expected to provide over 9 million t. It is apparent that strategies for increasing fish production from freshwater aquaculture should be directed towards horizontal and vertical growth of the sector. Under culture expansion, renovation and management of resources have to be done in such a manner that the average fish productivity from ponds and tanks would increase to 4-10 $\mathrm{t} \mathrm{ha}^{-1} \mathrm{yr}^{-1}$ from the current level of about $3.0 \mathrm{tha}$ ${ }^{1} \mathrm{yr}^{-1}$. Expansion, intensification and diversification of culture systems have been envisaged in the National Aquaculture Development Plan (Gopakumar et al., 1999). Aquaculture sector in India has to come up with timely strategies to cope with the future challenges of increased fish demand, selective consumers' choices, production of safe and quality fish protein and tapping the export earning among the many challenges. It is even more challenging that all these have to be done in the face of increased land and water scarcity, climate change, competition from other agriculture sector, labour shortage, shortage of raw materials besides satisfying the Code of Conduct for Responsible Aquaculture (CCRA) and Hazard Analysis at Critical Control Points (HACCP) in farming. If the country has to achieve its premium goal of Blue Revolution to ensure quality fish protein, the researchers and development machineries in the 
freshwater sector need to maintain pace of the aquaculture development at sound and sustainable levels.

\section{Acknowledgements}

The author is thankful to former colleagues in ICAR-CIFA, Bhubaneswar for their inputs in the present review. The author also wishes to place on record his sincere appreciation to Dr. S. D. Tripathi, Former Director, ICAR-CIFA, Bhubaneswar and ICAR-CIFE, Mumbai for his useful suggestions.

\section{Reference}

Chakrabarti, P. P., Chakrabarty, N. M. and Mondal, S. C. 2009. Breeding and seed production of butter catfish, Ompok pabda (Siluridae) at Kalyani Centre of CIFA, India. Aquac. Asia, 14: 33-35.

CIFA 2004. CIFA technologies. Central Institute of Freshwater Aquaculture, Bhubaneswar. Odisha, India.

DADF 2017. Annual report 2016-17. Department of Animal Husbandry, Dairying and Fisheries. Ministry of Agriculture, Government of India, $162 \mathrm{pp}$.

Das Mahapatra, K., Jayasankar, P., Saha, J. N., Murmu, K., Rasal, A. R., Nandanpawar, P., Patnaik, M., Sundaray, J. K. and Sahoo, P. K. 2016. "Jayanti" rohu: Glimpses from the journey of first genetically improved fish in India. Central Institute of Freshwater Aquaculture, Kausalyaganga, Bhubaneswar, $60 \mathrm{pp}$.

De Silva, S. S. and Soto, D. 2009. Climate change and aquaculture: potential impacts, adaptation and mitigation. In: Cochrane, K., De Young, C., Soto, D. and Bahri, T. (Eds.), Climate change implications for fisheries and aquaculture: overview of current scientific knowledge. FAO Fisheries and Aquaculture Technical Paper No. 530, FAO, Rome, p. 151-212.

FAO 2016. Fishery and aquaculture stastistics 2014. Food and Agricultural Organisation, Rome, 204 pp.

FAO 2017. National aquaculture overview: India. Country profile fact sheets. FAO Fisheries and Aquaculture Department, FAO, Rome. http://www.fao.org/fishery/ factsheets/en (Accessed 1 December 2017).

Gopakumar, K., Ayyappan, S., Jena, J. K., Sahoo, S. K., Sarkar, S. K., Satpathy, B. B. and Nayak, P. K. 1999. National freshwater aquaculture plan. Central Institute of Freshwater Aquaculture, Bhubaneswar, 75 pp.

Haylor, G. 2004. Poverty reduction and aquatic resources. Emerging trends and experiences in Asia-Pacific aquaculture 2003, NACA/FAO, Proceedings of Symposium hosted by the Government of Sri Lanka, 21- 25 April 2004. FAO/NACA.

ICAR 2005. Aquaculture technologies for farmers. Indian Council of Agricultural Research, New Delhi.
Jayasankar, P. 2014. Recent advances in freshwater finfish aquaculture: Prospects and constraints. In: Sinha, V. R. P. and Jayasankar, P. (Eds.), Aquaculture - New possibilities and constraints. Narendra Publishing House, New Delhi, India, p. 1-12.

Jayasankar, P. 2017. Freshwater aquaculture technologies for the second blue revolution: Opportunities for aquaculture entrepreneurship. In: Sinha, V. R. P., Gopal Krishna, Keshavanath, P. and Kumar, N. R. (Eds.), Social entrepreneurship in aquaculture. Narendra Publishing House, New Delhi, India, p. 147-158.

Jayasankar, P. and Giri, B. S. 2013. Striped catfish (Pangasianodon hypophthalmus) - Gift from Vietnam to Indian aquaculture industry. Fishing Chimes, 33 (1\&2): 36-40.

Jayasankar, P. and Barik, N. K. 2015. Promotion of PPPs for wider adoption of freshwater aquaculture technologies: Scope and strategies. In: Sinha, V. R. P., Gopal Krishna, Keshavanath. P. and Kumar, N. R. (Eds.), Social entrepreneurship in aquaculture, Narendra Publishing House, New Delhi, India, p. 57-67.

Jayasankar, P. and Das, P. C. 2015. Vertical expansion strategy for increased freshwater aquaculture production. Fishing Chimes, 35: 44-51.

Katiha, P. K., Jena, J. K., Pillai, N. G. K., Chakraborty, C. and Dey, M. M. 2005. Inland aquaculture in India: Past trend, present status and future prospects. Aquac. Econ, Manag., 9: $237-264$

Khan, H. A. 1969. Induced breeding of air breathing fishes. Indian Farming, 19: 26-28.

Kumar, K., Kumar, R., Mohanty, U. L., Saurabh, S., Sahoo, M., Mohanty, A. K. Sahu, A. K., Jena, J. K. and Jayasankar, P. 2012. Climbing perch, Anabas testudineus: Consumers' delicacy. Fishing Chimes 32(6): 40-43.

Kumar, K., Kumar, R., Mohanty, U. L., Saurabh, S., Sahu, B. B., Sahoo, M., Mohanty, A., Sahu, A. K. and Jayasankar, P. 2013. Snakehead fishes: Alternative candidate fish for diversification of aquaculture. In: Sinha, V. R. P. and Jayasankar, P. (Eds.), Aquaculture - new possibilities and constraints. Narendra Publishing House, New Delhi, India, p. $115-128$.

Kumar, S. 2016. Fisheries India. Commissioned by the Netherlands Embassy to India, National aquaculture sector overview India, $11 \mathrm{pp}$.

Mohanty, M., Jayasankar, P., Sahoo, L., Das, P., Das, B. K., Verma, D. K. and Routray, P. 2016. Early identification of hybrids of Indian major carp, Labeo rohita and Catla catla using nuclear marker-based multiplex PCR. J. Appl. Ichthyol., 32: 963-965. doi.org/10.1111/jai.13111.

Pillai, B. R., Mahapatra, K. D., Ponzoni, R. W., Sahoo, L., Lalrinsanga, P. L., Nguyen, N. H., Khaw, H. L., Mohanty, S., Sahu, S., Patra, G., Patnaik, S. and Eknath, A. E. 2011. Selective breeding of giant freshwater prawn Macrobachium rosenbergii for improved harvest weight in 
India. Asia-Pacific Aquaculture Conference, 17-20 January 2011, Kochi, India.

Roy, A. K. 2015. Public private partnership and aquaculture. In: Sinha, V. R. P., Keshavanath, P., Sharma, A. P. and Mohanty, B. P. (Eds.), Public private partnerships in Aquaculture. Narendra Publishing House, New Delhi, India, p. 17-31.

Salim, S. S., Pramod Kiran, R. B., Joshua, N. E. and Kumar, B. 2014. Challenges in food security: The fisheries and aquaculture policy perspectives in India. J. Aquat. Fish. Biol., 2(1): 24-31.

Sinha, V. R. P., Gupta, M. V., Banerjee, M. K. and Kumar, D. 1973. Composite fish culture in Kalyani. J. Inland Fish. Soc. India, 5: 201-208.

Sinha, V. R. P. and Jayasankar, P. 2014. Aquaculture - New possibilities and constraints. Narendra Publishing House, New Delhi, India, 280 pp.

Subasinghe, R., Soto, D. and Jia, J. 2009. Global aquaculture and its role in sustainable development. Rev. Aquac., 1: 2-9. doi.org/10.1111/j.1753-5131.2008.01002.x.
Sugiyama, S., Staples, D. and Funge-Smith, S. 2004. Contribution of fisheries and aquaculture in the AsiaPacific. Status and potential of fisheries and aquaculture in Asia and the Pacific. RAP Publication-2004/25, FAO Corporate Document Repository, FAO, Rome.

Thakur, N. K. and Das, P. 1986. Synopsis of biological data on Clarius batrachus (Linn.1758). Bull. No. 41. Central Inland Fisheries Research Institute, Barrackpore.

Tidwell, J. H. and Allan, G. L. 2001. Fish as food: Aquaculture's contribution. EMBO Rep. 2001, 2: 958-963. doi: 10.1093/ embo-reports/kve236.

Tripathi, S. D., Aravindakshan, P. K., Ayyappan, S., Jena, J. K., Muduly, H. K., Chandra, S. and Pani, K. C. 2000. New high in carp production in India through intensive polyculture. J. Aquac. Trop., 15: 119-128.

Vignesh, K., Kumar, V. S., Rajakumar, M., Chidambaram, P., Kanaga, V., Pasupathi, P. and Rajarajan, P. 2017. An analysis of socio-economic profile and constraints of the Indian major carps (IMC) seed rearing farmers in Thanjavur District, Tamil Nadu. Int. J. Fish. Aquat., 5(4): 308-310. 